\title{
Relaçōes antigênicas entre peixes comuns à bacia do rio Amazonas $\left(^{*}\right)$
}

\author{
Morris Reichlin (') \\ Bonnie J. Davis ${ }^{(2)}$
}

\begin{abstract}
Resumo
Utilizando antissoro para hemoglobinas de carpa e truta, as hemoglobinas de peixes comuns do rio Amazonas exibiram vastas reações cruzadas. Enquanto nenhuma hemoglobina de peixe precipitou com antissoro de truta 4 (componente anódico), muitas hemoglobinas participaram tanto com antissoro de truta 1 (componente catódico) ou com hemogiobina de carpa. Vários padrões de reatividade podem ser descritos entre as hemoglobinas polídispersas de várias espécies que foram analisadas por separação eletroforética dos componentes e uma determinação da habilidade de reagir dos componentes individuais com os dois tipos de antissoro. O mais notável foi a diferente reatividade notada entre os Siluriformes "catfish" onde as hemoglobinas dos "catfishes" de respiração aérea reagiram mais fortemente com o soro antitruta 1 do que com soro anticarpa enquanto as hemoglobinas de "catfish" respiração branquial se comportaram de modo recíproco.
\end{abstract}

\section{INTRODUÇÃo}

Entre as espécies de vertebrados, os peixes exibem um alto (se não o mais alto) grau de diversidade estrutural e funcional nas suas heglobinas. Entendendo esta diversidade molecular pode ser abordada por uma variedade de instrumentos analíticos. Métodos imunoquímicos estão em primeiro lugar na facilidade com que as relaçöes qualitativas entre as seqüências de amino-ácidos podem ser avaliada. Esta comunicação descreve os resultados de um levantamento imunoquímico qualitativo das $\mathrm{Hbs}$ de peixes comuns à bacia do rio Amazonas, próximo a Manaus, Brasil. $\mathrm{O}$ antissoro de coelho usado foi preparado contra $\mathrm{Hbs}$ de truta 1 e 4 e carpa. Embora nenhum desses peixes viva na bacia do rio Amazonas, estes antissoros provaram sua utilidade no reconhecimento das relações de Ordem e Família e permitiram um critério inicial dos tipos e distribuiçâo das cadeias polipeptidicas contidas nas hemoglobinas dos peixes do rio Amazonas. Algumas correlações notáveis foram feitas também entre propriedades antigênicas e propriedades fisiológicas das $\mathrm{Hbs}$ dos peixes estudados.

\section{MATERIAIS E MÉTODOS}

\section{PREPARAÇÃO DO ANTISSORO}

$\mathrm{O}$ antissoro foi preparado em coelhos para Hbs 1 e 4 de truta por uma dose e esquema descrito recentemente (Tan-Wilson et. al., 1976). O antissoro de coelho para um dos tipos eletroforéticos lentos de $\mathrm{Hb}$ de carpa foi preparado de maneira similar.

\section{PROPRIEDADES DO ANTISSORO}

As propriedades imunoquímicas quantitativas do soro antitruta utilizado foram descritas (Tan-Wilson et. al., 1976). Os resultados daquele estudo foram compatíveis com o fato de que $\mathrm{Hbs} 1$ e 4 de truta não compartilhava cadeias idênticas de polipeptideos e, além disso, que as duas Hbs eram imensamente diferentes tanto em suas cadeias $\propto$ como $\beta$. Nos métodos qualitativos usados neste estudo (difusão em agar descrita abaixo), estes soros comportaram-se como reagentes quase especificos; i.e. Hb 1 de truta não precipitam com anti $\mathrm{Hb} 4$ e $\mathrm{Hb} 4$ de truta precipitava apenas fracamente com antitruta $\mathrm{Hb} 1$. Anticorpos para $\mathrm{Hb}$ de carpa não precipitaram nem com truta $\mathrm{Hb} 4$ nem com truta $\mathrm{Hb} 1$; nem $\mathrm{Hb}$ carpa precipitou com antissoro para truta $\mathrm{Hb} 1$ e 4 . Assim, cada soro era um reagente que poderia ser usado para identificar determinantes antigênicos relacionados à $\mathrm{Hb}$ de truta 1,4 e hemo-

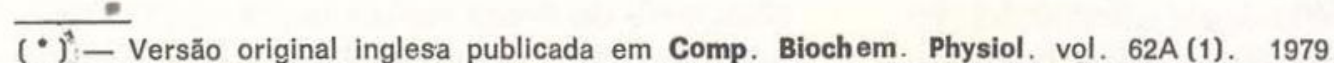

(1) - Department of Medicine, State University of New Kork at Bufalo, Bufallo N.y. 14215.

(2) - Department of Biology, San Francisco State Univer sity, San Francisco, California 94132.
} 
globina de carpa entre as hemoglobinas de muitas espécies de peixe estudados na IV expedição ao Amazonas. A natureza altamente específica destes antissoros está refletida por resultados que mostram a larga e independente distribuição de estruturas antigểnicas em hemoglobina de peixe reativas com Hbs antitruta e carpa.

\section{PREPARAÇÃo DA AMOSTRA}

Os peixes usados neste estudo foram coletados no rio Solimões e no rio Negro, próximo a Manaus, Brasil. Os peixes eram sangrados por punção cardíaca e o sangue coletado em solução salina $(1,7 \% \mathrm{NaCl})$ fria, heparinizada. As células vermelhas eram separadas no plasma por centrifugação a $5.000 \mathrm{~g}$ por 5 minutos numa centrífuga refrigerada Sorvall. Após 3 lavagens com salina fria, as células eram lisadas com tampão Tris frio, diluído $(0,001 \mathrm{M}), \mathrm{pH} 8,0$. A lise era realizada por 1 hora, então se adicionava $\mathrm{NaCl}$ para uma concentração final de $\mathrm{O}, \mathrm{IM}$, e o lisado centrifugado a $17.000 \mathrm{~g}$ por 20 minutos para remover partículas celulares. O sobrenadante limpo, vermelho, foi cuidadosamente transferido para um frasco limpo e guardado no refrigerador para uso posterior.

\section{ELETROFORESE EM POLIACRILAMIDA}

A eletroforese em gel de disco, usando $7 \frac{1}{2} \%$ de acrilamida a $\mathrm{pH} 8,9$ foram feitas segundo Davis (1964) e Ornstein (1964). A amostra de hemoglobina era reduzida para o estado ferroso pelo método descrito por Fyhn \& Sullivan (1975). A hemoglobina foi adicionada ao gel em quantidades suficientes para que os diferentes componentes pudessem ser visualizados sem coloração. $\mathrm{O}$ gel era então cortado em volta das faixas vermelho-pálido.

\section{DIFUSÃO EM AGAR}

A dupla difusão em agar foi realizada pelo métcdo de Ouchterlony (Reichlin, 1975). Os experimentos eram realizados em placas de $\mathrm{Pe}$ tri de plástico $60 \times 15 \mathrm{~mm}$ (Falcon \# 1007, Oxnard, California). Agarose (Aldrich Chemical Co., Milwaukee, Wis.) gel $(0,6 \%)$ foi dissolvido em solução de $\mathrm{NaCl} 0,9 \%$ feita com água deionizada, bidestılada. Os antissoros fo. ram usados em depósitos feitos com um furador de cortiça de $6 \mathrm{~mm}$ e o antígeno em depósitos de $4 \mathrm{~mm}$ de diâmetro em um arranjo septagonal. $O$ antissoro era usado sem diluição e a solução de $\mathrm{Hb}$ era utilizada em concentrações de 0,1 a $0,5 \mathrm{mg} \mathrm{Hb} / \mathrm{ml}$. Concentrações de hemoglobina maiores do que $2,0 \mathrm{mg} / \mathrm{ml}$ dissolviam muito do potencial de imuno precipitação mas a precipitação era reproduzível aos níveis mais baixos empregados. A precipitação era realizada à temperatura ambiente que no "Alpha Helix" variava entre $30-33^{\circ} \mathrm{C}$. As placas eram lidas com 6,12 e 24 horas. A estas temperaturas a precipitação estava invariavelmente completa com 12 horas.

\section{EXPERIMENTOS DE ABSORÇÃO}

A absorção foi realizada pela adição de um volume do hemolisado (concentração 1-5\%) que era $1 / 10$ do volume do antissoro. Isto resultou em uma concentraçẫo de $\mathrm{Hb}$ final de 1 a $5 \mathrm{mg} / \mathrm{ml}$ muito além da zona de equivalência de qualquer dos sistemas envolvidos. O soro absorvido era então utilizado no centro do depósito do arranjo septagonal com uma lista de hemoglobinas representativas de 26 espécies de peixes.

\section{RESUltados}

A primeira aproximação à análise antigênica das hemoglobinas de peixe era simplesmente testar suas reatividades em experimentos de difusão em gel com os 3 antissoros disponiveis: $\mathrm{o}$ antitruta $\mathrm{Hb} 1$, antitruta $\mathrm{Hb} 4$ e anticarpa $\mathrm{Hb}$. De todas as amostras de hemoglobina testadas, nenhuma precipitou com os antissoros para truta $\mathrm{Hb} 4$. A significaçăo desta dramática descoberta será determinada na discussão. Notou-se que um número significativo de hemoglobinas de peixe não precipitavam com nenhum antissoro. O mais notável entre estes foi afastado relacionamento dos elasmobrânquios (Potamotrygonidae) e sarcopterygians (Lepidosirenidae). Não surpreendentemente, $\mathrm{Hb}$ de caecilians adultas e fetais (Typhlonectes compressicauda) não precipitaram com nenhum antissoro. Dos Osteoglossidae, a $\mathrm{Hb}$ de Arapaima gigas precipitou apenas com soro anticarpa $\mathrm{Hb}$. Como pode ser visto na Tabela 1, todos os peixes caracídeos e gym. 
TABELA 1

\begin{tabular}{|c|c|c|c|}
\hline Familia & Espécies & $\begin{array}{c}\text { à } \\
\text { Trout } \\
1\end{array}$ & à \\
\hline Potamotrygonidae & Potamotrygon sp. & $\theta$ & 0 \\
\hline Lepidosirenidae & Lepidosiren paradoxa & 0 & 0 \\
\hline Osteoglossidae & $\begin{array}{l}\text { Osteoglossum } \\
\text { bicirrhosum } \\
\text { Arapaima gigas }\end{array}$ & 0 & 0 \\
\hline Characidae & $\begin{array}{l}\text { Triportheus sp. } \\
\text { Mylossoma sp. }\end{array}$ & & \\
\hline Curimatidae & Curimatus sp. & + & + \\
\hline Erythrinidae & $\begin{array}{l}\text { Hoplias malabaricus } \\
\text { Hoplerythrinus } \\
\text { unitaeniatus }\end{array}$ & + & + \\
\hline Prochilodontidae & Prochilodus sp. & + & + \\
\hline Cynodonitidae & Rhaphiodon sp. & + & + \\
\hline Hemiodontidae & Hemiodus sp. & + & + \\
\hline Gymnotidae & Gymnotus carapo & + & + \\
\hline Electrophoridae & $\begin{array}{l}\text { Electrophorus } \\
\text { electricus }\end{array}$ & + & + \\
\hline Rhamphichthyidae & Rhamphicthys sp. & + & + \\
\hline Doradidae & Pseudo doras & 0 & 0 \\
\hline Pimelodidae & Brachyplatystoma sp. & 0 & 0 \\
\hline & Pimelodus sp. & 0 & 0 \\
\hline Auchenipteridae & Auchenipterus sp. & 0 & 0 \\
\hline Ageneiosidae & Ageneiosus sp. & 0 & 0 \\
\hline Hypophthalmidae & Hypophthalmus sp. & 0 & 0 \\
\hline Callichthyidae & $\begin{array}{l}\text { Hoplosternum } \\
\text { littorale }\end{array}$ & + & $\operatorname{tr}$ \\
\hline Lorioariidae & Ancistrus sp. & + & + \\
\hline & Loricaria sp. & 0 & 0 \\
\hline & Hypostomus sp. & + & $\operatorname{tr}$ \\
\hline & Pterygoplichthys sp. & + & $\mathrm{tr}$ \\
\hline Belonidae & Potamorrhaphis sp. & + & + \\
\hline Synbranchidae & $\begin{array}{l}\text { Synbranchus } \\
\text { marmoratus }\end{array}$ & 0 & 0 \\
\hline Cichlidae & $\begin{array}{l}\text { Chaetobranchus } \\
\text { orbicularis }\end{array}$ & + & $\operatorname{tr}$ \\
\hline & Clchlosoma severum & + & $\mathrm{tr}$ \\
\hline Tetraodontidae & Colomesus psittacus & 0 & 0 \\
\hline
\end{tabular}

notideos precipitaram com ambos os antissoros. Entre os "catfishes", muitas espécies de 6 famílias (Doradidae, Pimelodidae, Ageneiosidae, Auchenipteridae, Loricariidae, Hypopthalmidae) não precipitaram com nenhum antisscro. Todas estas famílias, exceto Loricariidae eram de respiração branquial e só uma espéčie de Loricaria não precipitou com nenhum antissoro. Todas as espécies reativas de "catfishes" são de duas famílias de respi- ração aérea (Loricariidae, Callichthyidae) e a reação de precipitação foi muito forte com soro antitruta 1 mas fraca e esporádica com soro anticarpa.

\section{EXPERIMENTOS DE ABSORÇÃO}

Para investigar a possível reatividade de hemoglobinas de peixe que deixava de precipitar em gel de agar também como para explorar com mais detalhes a especificidade das reações de várias $\mathrm{Hbs}$, os experimentos de absorção foram compreendidos. A Tabela 2 resume os achados que demonstram várias coisas. Primeiro, há Hbs que estäo mais relacionadas à $\mathrm{Hb}$ de carpa do que à $\mathrm{Hb} 1$ de truta em suas antigenicidades. $O$ exemplo mais claro disto é $\mathrm{Hb}$ de $A$. gigas cuja absorção de reatividade com 18 das 19 espécies de $\mathrm{Hb}$ reativa com soro anticarpa enquanto atinge a reatividade de espécies só 2 das 23 amostras de $\mathrm{Hb}$ reativa com soro antitruta 1 . A $\mathrm{Hb}$ de Osteoglossum bicirrhosum é muito similar em seus padrões de absurção e apesar de sua deficiência em precipitar com soro anticarpa, absorve com êxito - com 18 das 19 espécies reativas de $\mathrm{Hb}$ com soro anticarpa. Absorção com $\mathrm{Hb}$ de $O$. bicirrhosum não tinha nenhum efeito na precipitação de quaisquer das amostras de $\mathrm{Hb}$ com soro antitruta 1 como nas 23 dos 23 precipitados de Hbs após absorção. No outro extremo de especificidade, a $\mathrm{Hb}$ de Ancistrus sp. absorve totalmente a reatividade com soro antitruta 1 mas apenas cerca de metade da reatividade com soro anticarpa. Absorção com um cichlide, Chaetobranchopsis orbicularis, a $\mathrm{Hb}$ removia cerca de $2 / 3$ da reatividade tanto com soro anticarpa como com o soro antitruta 1, enquanto a absorção com Triportheus sp., a $\mathrm{Hb}$ removia essencialmente toda a reatividade presente em ambos os soros. Finalmente, foi mostrado que várias $\mathrm{Hbs}$ que não conseguiam precipitar nenhum soro podiam remover uma significativa quantidade da reatividade de um dos dois antissoros usados neste estudo. Três Hbs de "catfish" de respiração branquial (Pimelodus sp., Pseudodoras sp. e Brachyplatystoma sp.) removeram quantidades variáveis da reatividade do soro anticarpa e exceto para Pimelodus sp., a $\mathrm{Hb}$ não tinha nenhum efeito sobre o soro antitruta 1. A Hb de Symbranchus 
marmoratus removia significativas quantidades da reatividade tanto do soro anticarpa quanto do soro antitruta 1 .

Entre as $\mathrm{Hbs}$ de peixe testadas desta for$\mathrm{ma}$, apenas a $\mathrm{Hb}$ de Lepidosiren paradoxa não conseguiu absorver qualquer atividade dos soros anticarpa e antitruta 1.

Deveria ser mencionado que mesmo depois da absorção do antissoro com as Hbs mais ativos desta relação (Ancistrus sp. e Triportheus sp.) e reatividade muito significativa de precipitina ainda permanecia com os antígenos homologos, $\mathrm{Hb}$ de Truta 1 e $\mathrm{Hb}$ de carpa. Estes padrões de reatividade encontrados entre as $\mathrm{Hb}$ de peixes examinados foram obtidos utilizando-se uma fração de anticorpos neste soro.

TABELA ?

Estudos de absorção Fx espécies testadas precipitando continuamente

\begin{tabular}{lrr}
\hline Absorvido com & a Carp & a Trout 1 \\
& & \\
\hline & & \\
Arapaima gigas & $1 / 19$ & $21 / 23$ \\
Osteoglossum bicirrhosum & $2 / 19$ & $23 / 23$ \\
Synbranchus marmoratus & $6 / 19$ & $13 / 23$ \\
Lepidosiren paradoxa & $19 / 19$ & $23 / 23$ \\
Triportheus sp. & $1 / 19$ & $0 / 23$ \\
Chaetobranchopsis orbicularis & $7 / 19$ & $6 / 23$ \\
Ancistrus sp. & $8 / 19$ & $0 / 23$ \\
Pimelodus sp. & $14 / 19$ & $19 / 23$ \\
Pseudo doras sp. & $15 / 19$ & $23 / 23$ \\
Brachyplatystoma sp & $12 / 19$ & $23 / 23$ \\
& &
\end{tabular}

ESTUDOS ELETROFORÉTICOS E CROMATOGRÁFICOS

Os componentes eletroforéticos polidispersos reagiam em padrões característicos quando eram analisados antigenicamente como espécies moleculares isoladas. Esses dados estão resumidos na Tabela 3 , na qual a intensidade da precipitação é graduada numa escala de 0-4+. Quatro padrões de reação foram observados. No padrão $A$, os componentes isolados da $\mathrm{Hb}$ de Arapaima gigas reagiram apenas com $\mathrm{Hb}$ de anticarpa. No padrão $\mathrm{B}$ que inclui todos os Characidae (Mylossoma sp.) como também os Erythrinidae, os componentes anódicos reagem invariavelmente mais fortemente com $\mathrm{Hb}$ de anticarpa do que com $\mathrm{Hb}$ antitruta enquanto os componentes catódicos reagem com antitruta $\mathrm{Hbl}$ melhor do que ou também como com o soro anti $\mathrm{Hb}$ de carpa. No padrão $\mathrm{C}$, todos os componentes do gel reagem igualmente bem com ambos os antissoros. As $\mathrm{Hbs}$ de peixes que exibiram este comportamento foram de Prochilodontidae. Gymnotidae, Rhamphichthyidae e Cichlidae. O último padrão observado era o dos múltiplos componentes que reagiram quase exclusivamente com soro antitruta 1 e fracamente com soro anticarpa. Tornou-se visível com $\mathrm{Hbs}$ de Ancistrus sp., Hoplosternum littorale e Hypostomus sp. Hbs isoladas em geis de poliacrilamida que os componentes catódicos reagiram muito mais fortemente do que os anódicos com o soro antitruta 1.

TABELA 3 - Reações representativas de precipiti. na de componentes eletroforéticos e isolados de $\mathrm{Hb}$ de peixe.

$\begin{array}{lcc}\text { Peixe Padrão } & \text { Anti- } & \text { Anti- } \\ \text { Carp } & \text { Trout 1 }\end{array}$

\begin{tabular}{|c|c|c|c|c|}
\hline \multirow[t]{2}{*}{ Arapaima gigas } & $\mathbf{A}$ & Rápido & $2+$ & 0 \\
\hline & & Lento & $2+$ & 0 \\
\hline \multirow[t]{2}{*}{ Mylossoma sp. } & $\mathbf{B}$ & Rápido & $4+$ & $1+$ \\
\hline & & Lento & 0 & $2+$ \\
\hline \multirow[t]{2}{*}{ Rhytiodus sp. } & & Rápido & 4 & $1+$ \\
\hline & & Lento & $1+$ & $1+$ \\
\hline \multirow[t]{3}{*}{ Rhapiodon sp. } & & Rápido & $3+$ & $1+$ \\
\hline & & Intermédio & $3+$ & $1+$ \\
\hline & & Lento & $3+$ & $3+$ \\
\hline \multirow[t]{4}{*}{ Ancistrus sp. } & $\mathbf{C}$ & 1 & 0 & 0 \\
\hline & & 2 & 0 & 0 \\
\hline & & 3 & 0 & 0 \\
\hline & & 4 & 0 & $4+$ \\
\hline \multirow[t]{2}{*}{ Hypostomus sp. } & & Rápido & 0 & $1+$ \\
\hline & & Lento & 0 & $4+$ \\
\hline \multicolumn{5}{|l|}{ Pterygoplichthys } \\
\hline \multirow[t]{2}{*}{ sp. } & & 1 & 0 & $2+$ \\
\hline & & 2 & 0 & $2+$ \\
\hline \multirow{2}{*}{ - } & & 3 & 0 & $2+$ \\
\hline & & 4 & 0 & $2+$ \\
\hline \multicolumn{5}{|l|}{ Rhamphichthys } \\
\hline \multirow[t]{4}{*}{ sp. } & D & 1 & $2+$ & $2+$ \\
\hline & & 2 & $2+$ & $2+$ \\
\hline & & 3 & $2+$ & $2+$ \\
\hline & & 4 & $2+$ & $2+$ \\
\hline
\end{tabular}




\section{DISCUSSÃo}

Os anticorpos antitruta 1 e anticarpa presentes no soro de coelho reagem com determinados antigênicos das hemoglobinas de todos os peixes teleosteos examinados. Aquelas $\mathrm{Hbs}$ que não absorveram precipitados significativamente a reatividade do antissoro. A Hb de Lepidosiren paradoxa, por outro lado, não parece ter nenhuma atividade antigênica demonstrável com esses soros e deve estar muito distantemente relacionada em suas seqüências de $\mathrm{Hb}$ de todos os peixes teleósteos e, neste sentido, explica-se a delimitação da reatividade do antissoro empregado.

Encontramos notável e claro padrão de distribuição de estruturas antigênicas entre as $\mathrm{Hbs}$ de peixes que relacionam diretamente tanto as cadeias polipeptídicas das $\mathrm{Hbs}$ de truta 1 ou de carpa. Também é notável a ausência de atividade precipitante de qualquer das $\mathrm{Hbs}$ de peixe com um potente antissoro de $\mathrm{Hb} 4$ de truta. Como somente um único soro foi estudado, a generalização de tal achado precisa ser encarada com certa precaução, mas a ausência de reatividade sugere a seguinte explicação. A seqüência primária da $\mathrm{Hb}$ 4 de truta tem evoluído para um alto grau que exibe pouca semelhança com as seqüências primárias de outras Hbs de peixe que determinam as estruturas antigênicas dessas proteínas reativas com o antissoro de coelho. Desde que argumentos convincentes podem ser feitos de que a antigenicidade de uma proteína reflete primariamente sua superfície (Reichlin, 1975) e a superfície reflete a maioria dos átomos na proteína, conclui-se que a ausência significativa de reatividade causada, expressa que a grande maioria dos resíduos da superfície de $\mathrm{Hb} 4$ de truta é diferente dos resíduos de superfície de todas as outras Hbs de peixe das espécies examinadas.

De modo inverso a presença de atividade de precipitação entre muitas $\mathrm{Hbs}$ de peixe com antissoro para $\mathrm{Hb} 1$ de truta e de $\mathrm{Hb}$ de carpa sugere que é provável que grandes porções da superfície de tais Hbs possuam grande semeIhança de seqüência com $\mathrm{Hbs} 1$ de truta e carpa respectivamente. Comparativamente mais intereessante do que essas conclusões, são os padrões de distribuição de reatividade dos dois antissoros empregados.
Os experimentos eletroforéticos e cromatográficos garantem a seguinte interpretação dos dados. Entre as $\mathrm{Hbs}$ de peixes caracoides, os determinantes antigênicos relacionados à $\mathrm{Hp}$ de carpa são largamente distribuídos nos componentes eletroforéticos anódicos enquanto os determinantes relacionados à truta $1 \mathrm{e}$ distribuídos largamente nos componentes catódicos. As propriedades funcionais dos dois tipos eletroforéticos de $\mathrm{Hb}$ foram estudados em Mylossoma sp. Isto está refletido no diferente comportamento funcional dos dois componentes como as moléculas anódicas de Mylossoma sp. que são Hbs típicas de peixe com um efeito Root e uma alta sensibilidade da afinidade aos fosfatos orgânicos. O componente catódico de Mylossoma não possui efeito Bohr e é insensivel a fosfatos orgânicos. Isto reflete fielmente as propriedades funcionais das Hbs usadas para deduzir o antissoro empregado; i.e. o componente anódico se assemelha com $\mathrm{Hb}$ de carpa enquanto o componente catódico se assemelha à $\mathrm{Hb} 1$ de truta nas características funcionais.

Tais achados sugerem que os gens correspondentes às cadeias polipeptídicas das espécies anódicas e aqueles gens correspondentes às cadeias polipeptídicas de espécies catódicas tem evoluído de gens ancestrais nos quais os produtos do gens preferencialmente se combinam e não se associam ao acaso; i.e. para formar híbridos. É provável que nas células vermelhas de Mylossoma sp. como nas células vermelhas de truta (Brunori et al., 1974) ambas as $\mathrm{Hbs}$ são encontradas na mesma célula.

Em contraste com esta situação, várias espécies de peixe foram examinadas nas quais a característica dos determinantes antigênicos tanto da truta 1 como de carpa residiam nas mesmas moléculas freqüentemente de mobilidade eletroforética largamente diferente. Isto foi visto com $\mathrm{Hbs}$ de peixes cichlid, gymnotid e rhamphichthyid. Nesses casos, as cadeias polipeptídicas produzidas pelo gens em carpa e truta 1 como polipeptídeos são encontrados distribuídos juntos em todas as moléculas de $\mathrm{Hb}$ encontradas. As estruturas minuciosas e propriedades funcionais de tais $\mathrm{Hbs}$ são de grande interesse. 
Finalmente, a mais notável correlação desse estudo envolve a distribuição de antigenicidade específica relacionada às estruturas de truta e os "catfish" de respiração facultativa. Todos os "catfishes" de respiração aérea examinados (exceto Loricaria sp.) precipitaram fortemente com soro antitruta 1 e uma dessas $\mathrm{Hbs}$ (Ancistrus sp.) absorve toda a atividade de precipitação para as outras $\mathrm{Hbs}$ de peixe do soro antitruta 1. Em contraste, nenhuma "catfish" de respiração branquial precipitou com soro antitruta 1. Das 3 espécies de $\mathrm{Hb}$ axaminadas para a habilidade de absorver atividade da antitruta 1 , somente $\mathrm{Hb}$ de Pimelo. dus sp. mostrou atividade significativa. Por outro lado, todas as $3 \mathrm{Hbs}$ absorveram significativamente atividade do soro de $\mathrm{Hb}$ anticarpa. Assim, parece que os "catfish" de respiração branquial são mais proximamente relacionados à $\mathrm{Hb}$ de carpa na semelhança das cadeias polipeptídicas. Claramente, mais do que qualquer outra ordem de peixe estudada, tem sido a evidência nas hemoglobinas que suportam a idéia de que as espécies de "catfish" de respiração branquial e aérea divergiram no sentido evolucionário a um longo tempo atrás.

Há uma aparente relação entre respiração aérea e a presença de uma $\mathrm{Hb}$ que precipita com antitruta 1 por um lado e a ausência de tal antigenicidade nos "catfish" de respiração branquial. Se essas relações refletem somente relações de "familia" ou se também refletem rigorosamente diferenças funcionais entre estas familias de peixes é de grande interesse saber.

\section{AGRADECIMENTOS}

Este trabalho foi financiado pelo GRANT PCM-06451 do National Sciense Foundation para estudos no R/V "Alpha Helix". Agradecemos aos brasileiros por sua ajuda e por fazer possível o "Alpha Helix" subir o Amazonas. Desejamos agradecer ao capitão Clark e à tripulação por sua cooperação. B.J.D. agradece o financiamento da viagem feito pelo Joseph Henry-Marsh Fund da National Academy of Sciences e da San Francisco State University.

\section{SUMMARY}

Utilizing antisera to carp and trout hemoglobins, the hemoglobins of fish common to the Amazon River Basin exhibited extensive cross reactions. While no fish hemoglobin precipitated with antiserum to trout 4 (anodal component), many hemoglobins precipitated with either antisera to trout 1 (cathodal component) or carp hemoglobins. Several patterns of reactivity could be described among the polydispcrse hemoglobins of various species which were analyzed by the electrophoretic separation of the components and an assessment of the ability of individual components to reach with the two types of antisera. Most striking was the different reactivity noted amongst the catfishes where the hemoglobins of air-breathing catfishes reacted more strongly with anti-trout 1 serum than with anticarp serum while the hemoglobins of the water-breathing catfishes behaved in reciprocal fashion.

\section{BIBLIOGRAFIA}

Brunori, M.; Giardina, B.; Antonini, E.; Benedetti, P.A. \& BInNChini, G.

1974 - Distribution of the Haemoglobin components of trout blood among the erythocytes: Observations by single cell spectroscopy. J. Mol. Biol. 86, 165-169.

DAvis, B.J.

$$
\begin{aligned}
& 1964 \text { - Disc electrophoresis - Il Method and } \\
& \text { application to human serum proteins. } \\
& \text { Ann. N.Y. Acad. Sci. 121, 404-427. }
\end{aligned}
$$

Fyhe, U.E.H. \& B. Sullivan

1975 - Elasmobranch hemoglobins : dimerization and polymerization in various species. Comp. Biochem. Physiol. 50B, 119-129.

REICHLIN, M.

1975 - Amino acid substitution and the antigenicity of globular proteins. Adv. in Immunol. 20, 71-119.

TAN-WILSON, A.; REICHLIN, M.; BRUNORI, M.; \& Noble, R.W.

1976 - The virtual absence of antigenic cross reactivity between functionally distinct trout heimoblobins. Eur. J. Biochem. $71,125-129$. 